\title{
LA LITERATURA ECUATORIANA EN LAS TESIS DOCTORALES DE LAS UNIVERSIDADES \\ NORTEAMERICANAS DESDE 1943 A 1985
}

\author{
POR \\ OSWALDO ROMERO ARTETA \\ Center for Latin American Studies, Pittsburgh
}

Esta es una reseña informativa, no evaluativa, de la investigación universitaria de nuestra literatura. He añadido dos tesis de universidades inglesas para mayor información.

Algunas de estas disertaciones, corregidas y aumentadas, se han publicado como libro aparte y título diferente.

No he podido leerlas todas. Pero para quien le interese puede pedirlas por correo a University Microfilms International. P. O. Box 1764, Ann Arbor, MI. 48106.

1943 Terán, Carlos Manuel: «Remigio Crespo Toral: el hombre, su vida y su obra». University of California.

1951 Siegel, Rubén: «The Group of Guayaquil: A study in Contemporary fiction». University of Wisconsin. Director: Eduardo Neale Silva.

1952 Smither, William J.: «The regional and social aspects of the Contemporary Ecuadorean Novel (1920-1950)». Tulane University. Director: Daniel S. Wogan.

1953 Schwartz, Kessel: «The Contemporary Social Novel of Ecuador». Columbia University. Director: Andrés Iduarte.

1955 Da Silva, Zenia S.: «The Contemporary Ecuadorean Novel». New York University. Director: F. M. Thompson.

1957 Harth, Dorothy: «The poetic World of Carrera Andrade». Syracuse University. Director: Otto Olivera. 
1959 Southard, Gordon: «The Indigenista novel in Spanish America». University of Chicago. Director: Bernardo Blanco González.

1964 Allison, Wayne Lewis: «A thematic Analysis of the Contemporary Ecuadorian Novel». University of New Mexico.

1968 Robles, Humberto E.: «La estética de José de La Cuadra». Northwestern University.

1970 Otero, José: «Humberto Salvador: el hombre, sus temas y su creación». University of New Mexico.

1971 Gilmore, Robert Alfredo: «Pareja-Diezcanseco as a novelist». University of Nebraska.

Gold, P. J.: «The Literature of the 'Indigenista' movement in the Andean Republic since 1889». Oxford University.

Puente, José Enrique: «The influences of Bernardin de Saint-Pierre, Chateaubriand and James Fennimore Cooper in Juan León Mera's Cumandá» (texto en español). Director: Alfredo Lozada.

Como conclusión, el autor asegura haber demostrado las grandes influencias de los tres escritores en Mera, pero también las importantes diferencias de su novela.

Rabassa, Clementine Christos: «Demetrio Aguilera-Malta and the Epic Tradition». Columbia University.

1975 Beardsell, P. R.: «Ecuador, exile and quest for meaning in the works of Jorge Carrera Andrade». Sheffield University.

1976 Córdova, José Hernán: «Itinerario Poético de Jorge Carrera Andrade». Cornell University.

Es una disertación sobre la morfología de la expresión poética, pero sobre todo de la estructura del pensamiento y significado interno de la poesía de Carrera Andrade.

1977 Walker, Michael Lee: «The Black Social Identity in Selected Novels of Nelson Estupiñán Bass and Adalberto Ortiz». University of California, Riverside. Director: William Megenney.

El fin de esta tesis es examinar hasta qué punto dos escritores negros ecuatorianos creen en la existencia de una democracia racial en el Ecuador y en 
toda Hispanoamérica, sin dejar de comparar sus méritos literarios en la prosa social de los escritores ecuatorianos.

Valverde, María Eugenia: «La Narrativa de Aguilera Malta: un aporte a lo real-maravilloso». Rutgers University. The State University of New Jersey (New Brunswick). 146 pp. Director: Luis Mario Schneider.

Es la demostración de la gran contribución que ha tenido Aguileta Malta al «realismo mágico» latinoamericano.

1978 Valle, Angela María: «Lo erótico en la narrativa de AguileraMalta». Michigan State University.

Las conclusiones de la tesis son que: 1) el erotismo en Aguilera Malta se basa en principios éticos; 2) es un elemento estético mediante el cual logra el autor la integración de los diversos niveles de la realidad, y 3) le sirve para obtener la fusión artística y vital como expresión integral del ser humano.

1979 Aguilar Monsalve, Luis Antonio: «Alfredo Pareja Diezcanseco y su novela sociopolítica». University of California, Los Angeles. 327 pp. Director: John A. Crow.

Se demuestra que la narrativa de A.P.D. se distingue de la novela indianista o de la social pura hispanoamericana porque describe íntimamente la realidad social del trabajador ecuatoriano, descubriendo la realidad psicológica del hombre marginado por un mundo lleno de injusticias sociales y políticas. El análisis de la técnica como los artificios empleados para presentar un mundo parejiano, como parte de la literatura, es más importante todavía, ya que al final la presencia de A.P.C. como novelista se justifica en el hecho de llegar a ser un escritor de un profundo contenido social y político.

Baxter, Edwin Smith: «Reevaluation of Jorge Icaza's 'Huasipungo'». State University of New York at Binghamton. $177 \mathrm{pp}$.

Comienza con una evaluación de la crítica aparecida desde 1934 como punto de partida para el estudio de la obra dentro del marco circunstancial histórico, filosófico y político del Ecuador y Sudamérica. Estudia también los problemas de lenguaje de la obra y del Ecuador en general, concluyendo con la reafirmación del puesto distinguido del autor en su tiempo.

MacDonald, Regina Lee Harrison: «Andean Indigenous Expression: A Textual and Cultural Study of Hispanic-American and Quichua Poetry in Ecuador». University of Illinois at UrbanChampaign. 343 pp. 
Primeramente analiza la imagen del indio presentada en la poesía española escrita por literatos ecuatorianos para comparar y discutir con la propia imagen del indio revelada en la contemporánea poesía quichua recogida en las comunidades indígenas del Ecuador presente. Varios poemas quichuas incluidos en la «Antología ecuatoriana» de Mera son también analizados, juntamente con un estudio semiótico del poema más antiguo, «Atahualpa huañtii». El capítulo $V$ estudia la función del vocabulario quichtia en la obra de J. Carrera Andrade, G. H. Mata y César Dávila Andrade. E1 capítulo final, «La auténtica voz del indio», ofrece una discusión de etnopoética con relación a los himnos quichuas prehispánicos y la poesía quichua contemporánea. Al final del capítulo se transcriben modelos de cortesanía, erotismo, interacción matrimonial y étnicas encontrados en los poemas quichuas grabados por la autora en la altiplanicie y valles andinos de las comunidades indígenas del Ecuador.

Mendoza, Alfredo Aguayo: «Dialogue with the Public: Espejo, Lizardi, and Hidalgo». University of California, Irvine. 198 pp. Director: Seymour Menton.

Indica el autor que Espejo está entre los precursores que contribuyeron a destruir los cimientos filosóficos de la administración colonial, especialmente con su Nuevo Luciano, que refleja la influencia creciente del neoclasicismo y fue dirigida a la clase alta de su sociedad, afectada con problemas de metafísica natural. Los tres autores tuvieron una influencia profunda en la literatura que se desarrollaba en Latinoamérica, estimulando el nacionalismo para un autogobierno.

1980 Beane, Carol Anne: «The Characterization of Blacks and Mulattoes in Selected Novels of Colombia, Venezuela, Ecuador and Peru». University of California, Berkeley. 205 pp.

Esta tesis investiga la manera cómo novelistas de varios países hispanoamericanos, con un sustancial elemento afrohispánico en su población, lo sienten y representan. El estudio de la caracterización está organizado alrededor de tres períodos de significativo interés por los negros y mulatos en las novelas de Venezuela, Colombia, Ecuador y Perú. María, para el primero; para el segundo, el período de reconsideración y vindicación, Matalaché, de López Albújar; Pobre negro, de Rómulo Gallegos; Las lanzas coloradas, de Arturo Uslar Pietri; Baldomera, de Pareja Diezcanseco, y Cumboto, de Ramón Díaz Sánchez. El tercer periodo, que se sobrepone al segundo, en cuanto el negro vtelve a ser víctima, pero bajo un diferente ángulo: el de protesta social y resistencia. Adalberto Ortiz, en Yuyungo, examina la expresión de una conciencia individual, mientras Zapata Olivella, en Corral de negros, intenta describir la realización colectiva de las fuerzas que dominan los diversos caracteres. Y concluye que aunque las imágenes de negros y mulatos en todas estas novelas son psicológica y estéticamente deficientes en una manera u otra, están, sin embargo, válida y artísticamente comprometidos con la realidad de Latinoamérica. 
1981 Cevallos-Candau, Francisco J.: «La poesía de Juan Bautista Aguirre». University of Illinois at Urban-Champaign. $275 \mathrm{pp}$.

Luego de situar a Aguirre en su tiempo y en su escuela barroca colonial, que difería de la barroca peninsular, divide sus obras en tres principales categorías: la religiosa, la mitológica y la miscelánea. En esta última sección incluye los poemas morales, amatorios y satíricos. Estudia cada poema analizando en cada uno de ellos la tradición literaria a la que pertenecen, desde las fuentes clásicas hasta Sor Juana, recalcando cuando Aguirre es original en el tema. Un análisis estilístico y estructural ayuda a la comprensión del significado dentro de la estética de las imágenes, para concluir que Aguirre es uno de los tres grandes poetas barrocos de la América hispánica, con Del Valle Caviedes y Sor Juana Inés de la Cruz.

Newman, Ronna Smith: «Life and Works of Adalberto Ortiz». Northwestern University. 227 pp. Directores: Frederick S. Stimson y Humberto E. Rogles.

Este estudio explora la relación entre la vida y las obras de A. O.; trata de descubrir también las influencias literarias que recibiera y, sobre todo, trata de discernir la evolución de sus escritos, apoyado en entrevistas personales y abundante correspondencia epistolar. La carrera literaria la divide en tres fases, que van de la angustia existencial al optimismo y sarcasmo, con sus antipoesías. Esta carrera también revela una pauta en su vida: a mayor éxito literario y aceptación en la sociedad, una menor preocupación por la protesta racial, social e innovación artística.

1983 Norman, James Earl: «Ortiz's Juyungo and Icaza's Huasipungo: A Comparative Study of Narrative and Theme». The Florida State University. 115 pp. Director: Louis C. Bourgeois III.

Se trata de determinar los planes y artificios que han usado los dos atitores en su narración. Se analiza las diferentes técnicas incluyendo el monólogo interior, la similitud, anáfora, repetición, rima, ritmo, lenguaje y otras más, especialmente estudiadas en el capítulo III. El IV abarca una sinopsis y análisis de los principales caracteres de la novela y el último resume las semejanzas y diferencias.

Waag, C. Michael: «The Ecuatorian Novel of the 1970s in the Context of its Historical and Literary Past». University of Illinois at Urban-Champaign. 565 pp. Director: Thomas C. Meehan.

La novela ecuatoriana ha reflejado tradicionalmente la evolución social y económica de la República. Esto es especialmente verdadero en el período 1930-1940, con Jorge Icaza y el Grupo de Guayaquil. En las dos décadas posteriores estos nombres ceden la nombradía al grupo de la Nueva Novela de otros países latinoamericanos. Durante los años setenta hay un nuevo renacer, con los antiguos que remozan su estilo y un grupo de jóvenes de 
considerable mérito literario y significación histórica. Concluye especulando sobre las nuevas direcciones que la novela ecuatoriana ha tomado en los setenta, el grado de influencia de la tradicional novelística nativa y cómo han sido influidos por la Nueva Novela de otros paîses latinos. Waag vivió tres años en Ecuador.

1984 Espinoza, Herbert O.: «Class Struggle and Historical Determinism in the Ecuadorean Novel» (texto en español). University of California, San Diego. 188 pp. Directores: Carlos Blanco y Jaime Concha.

Esta investigación pretende estudiar la narrativa nacional ectuatoriana dentro de los límites de su contexto histórico. Desde 1879, con Cumandá, hasta 1976, con Siete lunas y siete serpientes, la historia literaria del Ecuador parece estar modelada por la revolución liberal de 1895 y la caída de la economía de exportación al final de los treinta. Claramente dividido por estos dos acontecimientos, el proceso literario ecuatoriano presenta tres períodos definidos: la narrativa del precapitalismo burgués (1879-1904); la de la crisis del pensamiento burgués, que da énfasis a las tempranas tendencias sociales, que incluye a novelas indigenistas y urbanas como El muelle y Las cruces sobre el agua, y en tercer lugar, la narrativa de tendencia mítica, que aparece después de un largo período de silencio y que se incorpora a la gran corriente del llamado boom de la novela latinoamericana. Esta nueva narrativa rechaza el criterio divisionista de Sierra y Costa, antes usado, y propone como una alternativa la periodización de la literatura ecuatoriana, como un proceso orgánico e integral que toma en consideración no sólo los efectos económicos y las consecuencias sociales causadas por la intromisión y expansión de los modos capitalistas de la producción, sino que intenta descubrir la opresión y la lucha de las clases marginadas del Ecuador.

Martínez Echazábal, Lourdes: «La mulatez y su expresión literaria en tres novelas hispanoamericanas: 1928-1950». University of California, San Diego. 131 pp. Director: Jaime Concha.

Las obras estudiadas ilustran algunos de los estereotipos raciales y culturar les en torno al mulato, y así reflejan ciertas posturas ideológicas relativas a la conceptualización de la mulatez en el ámbito político y literario. Analiza luego empíricamente Matalaché, de López Albújar; Juyungo, de Adalberto Ortiz, y Cumboto, de Díaz Sánchez. Mediante algunos elementos de crítica sociohistórica y psicosocial, estudia el motivo de estas obras. Y, por último, muestra que en la literatura mulatista se da un desplazamiento del énfasis de lo racial a lo cultural, que se proyecta literariamente en una nueva imagen del mulato a partir de los años treinta. Desplazamiento en gran parte retórico, no debido a un cambio de actitud racial, sino a la transmutación del racismo cientificista en un neorracismo de envoltura culturalista. 
Pianca, Marina: «El Teatro Latinoamericano frente a la Historia: 1959-1980». University of California, Los Angeles. 502 pp. Director: Gerardo Luzuriaga.

Se explora el desarrollo del Nuevo Teatro en Latinoamérica en relación con los acontecimientos históricos del último cuarto de siglo divididos en tres partes: 1959-1968, 1968-1974 y 1974-1980. Cada período contiene una parte de historia, otra de texto y una llamada de «transición», en que se exponen las causas del nuevo movimiento teatral. En el segundo período se analizan algunos festivales de teatro en Latinoamérica, y entre ellos el de Quito.

1985 Cisneros, José Julio: «La Evolución de la Novela Ecuatoriana: de la Generación del 30 a la Década de los Setenta». University of Pittsburgh. 296 pp. Directores: John Beverley y Keith McDuffie.

El propósito general es demostrar que la novela como género es agente de cambio social e ideológico en la sociedad. Se analiza las obras de la generación del 30 para revisar los conceptos que originaron el consentimiento crítico de estas obras. Se indaga en particular la razón para que esta narrativa haya tenido solamente un valor «extraliterario» o «documental». Luego del contexto social histórico de ellas, se las presenta en una visión panorámica. Las novelas de la transición del treinta a los setenta se estudian en el capítulo III, deteniéndose en Los nuevos años, de Pareja Diezcanseco, y en El chulla Romero y Flores, de Icaza. En el último capítulo se concentra en la narrativa de los setenta; incluye una revisión histórico-política de la realidad ecuatoriana, reparando en el efecto que la explotación y exportación del petróleo tuvo en la sociedad. Demuestra que los rápidos cambios sociales originaron no solamente una nueva sociedad, sino también un nuevo tipo de novela, que representa una variante a la Nueva Novela Latinoamericana. Se detiene en la novela de Adoum Entre Marx y una mujer desnuda, para luego anotar otras publicaciones importantes, que marcan una nueva dirección en la narrativa del Ecuador.

Hampton, Janet Jones: "The Image of the Black Woman in the Spanish-American Novel: A Study of Characterization in Selected Spanish-American Novels». The Catholic University of America. 197 pp.

Examina, entre otros, a Miguel Angel Asturias, Guillermo Cabrera Infante, Nelson Estupiñán Bass, Alfredo Pareja Diezcanseco, Arturo Uslar Pietri y Cirilo Villaverde. Indica las omisiones y errores en la caracterización y muestra las imágenes positivas representadas, aduciendo ejemplos de mujersigno dentro de la semiótica. Para este fin emplea la crítica feminista como base del análisis. Concluye estableciendo la validez de esta crítica como método analítico, ya que es una técnica efectiva para representar la imagen positiva de la mujer negra, imagen frecuentemente preterida en el tradicional enfoque del asunto. Termina con una valoración de los diversos tipos de mujer negra citados en la tesis. 
Mattrella, Anne Laura: «A Computer Based Analysis of Three Latin-American Novels Related to the Theme of the Indian» (texto en español). The Catholic University of America. 276 pp. Director: Mario Rojas.

Este estudio analiza, por medio de la computadora, el tema del indio en la novela romántica Cumandá, de Juan López Mera; la naturalista Aves sin nido, de Clorinda Matto de Turner, y la posnaturalista Sumag Allpa, de Humberto Mata. La computadora se usó en el léxico-análisis, que examinó la frecuencia de las palabras de cada novela y correlacionó varios campos semánticos con el tema indio, para, en el análisis sintáctico, examinar la estructura fraseológica de cada novela. Los data generados por la computadora fueron comparados con los obtenidos por los métodos tradicionales. El análisis estructural dio como resultado varios parámetros que revelaron la manera como cada escritor presenta el tema y la época literaria en que fueron escritos. Así, Cumandá revela la tendencia de un romanticismo progresivo; Aves sin nido, la coexistencia del romanticismo con el realismo, y define con más claridad la expresión de lucha de clases en Sumag Allpa. Este estudio confirma que la computadora es un instrumento útil para, cuantitativamente, verificar o refutar la crítica intuitiva y descubrir modelos verbales que llevan a nuevas percepciones, que de otra manera hubieran quedado ignoradas. 